Archives de sciences sociales des religions

116 | octobre - décembre 2001

Varia

\title{
Gad Freudenthal (ed.), AIDS in Jewish Thought and
}

Law

Hoboken (N.J.), KTAV Publishing House, Inc. 1998, 175 p. (index)

Régine Azria

\section{(QpenEdition}

\section{Journals}

Édition électronique

URL : http://journals.openedition.org/assr/463

DOI : $10.4000 /$ assr.463

ISSN : $1777-5825$

Éditeur

Éditions de l'EHESS

Édition imprimée

Date de publication : 2 octobre 2001

Pagination : 93-156

ISBN : 2-222-96712-0

ISSN : 0335-5985

\section{Référence électronique}

Régine Azria, "Gad Freudenthal (ed.), AIDS in Jewish Thought and Law», Archives de sciences sociales des religions [En ligne], 116 | octobre - décembre 2001, document 116.20, mis en ligne le 21 novembre 2005, consulté le 24 septembre 2020. URL : http://journals.openedition.org/assr/463 ; DOI : https:// doi.org/10.4000/assr.463 
siècle jusqu'au début des années 1980. Dans ce panorama ils soulignent la façon dont l'Église catholique dans ces pays prit progressivement ses distances à l'égard de ses traditionnels alliés conservateurs et comment elle développa de nouvelles stratégies visant une plus forte influence dans la vie politique nationale. Deux tiers de l'ouvrage sont ensuite dédiés à l'analyse du rôle joué par l'Église catholique au Chili (chap. 4 et 5) et au Pérou (chap. 6 et 7 ) dans la transition des gouvernements militaires vers des gouvernements civils ainsi que dans la recherche d'une consolidation de la vie démocratique au cours des années 1980.

M.F. et B.H.S. s'appuient sur une bibliographie choisie (en grande partie chilienne, péruvienne et états-unienne) qui avait déjà analysé les relations de l'Église catholique avec la vie politique au Chili et au Pérou mais d'une façon séparée pour les deux pays. Leur grand apport consiste à travailler la problématique dans une perspective comparatiste qui leur permet d'expliquer pourquoi l'Église catholique chilienne a pu jouer un rôle important dans la transition vers la démocratie et pourquoi tel ne fut pas le cas au Pérou. Les AA. complètent leur documentation avec plus de 150 entretiens réalisés entre 1987 et 1990 avec des intellectuels et des leaders catholiques chiliens et péruviens, et avec une série d'enquêtes faites à Santiago du Chili et à Lima sur les comportements politiques et religieux des catholiques.

En articulation avec le sujet central de la recherche, les AA. nous montrent aussi, en filigrane, d'autres dynamiques qui ont affecté les relations entre l'Église catholique et les pouvoirs politiques pendant la période, à savoir : la radicalisation de gauche d'un secteur de l’Église lié au mouvement de la théologie de la libération; la pentecôtisation de pans importants de la population; et une progressive sécularisation de la société, et tout cela en conjonction avec un processus de "restauration catholique » à partir de 1978, début du pontificat de Jean-Paul II.

Rodolfo de Roux.

FREUDENTHAL (Gad), ed.

AIDS in Jewish Thought and Law. Hoboken (N.J.), KTAV Publishing House, Inc. 1998, 175 p. (index).

G.F. est chercheur, spécialiste de l'histoire des sciences et de la philosophie juive médiévale. Aussi n'est-il pas étonnant qu'il se soit intéressé à la façon dont les autorités religieuses juives se sont emparées des questions susci- tées par l'irruption du sida dans nos sociétés. Il nous livre ici un ouvrage dans lequel il a rassemblé des points de vue juifs "autorisés» émanant de courants et de sensibilités religieux divers, exprimés et/ou publiés entre 1986 et 1995, le tout étant précédé d'une consistante introduction écrite de sa main.

Le sida soulève une multitude de questions qui vont bien au-delà de la maladie elle-même, de son origine, de son mode de diffusion, des traitements disponibles, de son coût humain et économique. Les réponses ici apportées sont évidemment tributaires de l'avancée des connaissances scientifiques et de l'extension de la pandémie elle-même, mais elles dépendent tout autant du niveau (théologique, éthique, normatif) auquel les penseurs et décisionnaires juifs choisissent de se situer pour aborder le phénomène sociétal qui s'est développé autour de la maladie, et des références scripturaires sur lesquelles ils prennent appui pour fonder leurs avis. Ce qui explique la diversité des réponses, y compris au sein d'une même famille de pensée.

Au moment où ces avis sont exprimés, il est encore admis que le sida affecte des personnes appartenant essentiellement à deux types de groupes, les homosexuels et les drogués, autrement dit des hommes et des femmes que, pour des raisons différentes, le judaïsme considère comme des "pécheurs ». Il s'agit donc de se prononcer à la fois sur la nature théologique de la maladie et sur l'attitude à adopter vis-à-vis des malades concernés : le sida doit-il être considéré comme un châtiment divin infligé à des pécheurs ou comme la conséquence logique d'une conduite condamnable mais susceptible d'être amendée ? L'obligation de venir en aide aux malades et aux affligés (les soigner, leur rendre visite, etc.) s'applique-t-elle aussi aux personnes atteintes du sida ? Les modes de prévention recommandés par les autorités sanitaires (utilisation de préservatifs et distribution d'aiguilles propres) sont-ils acceptables aux yeux du judaïsme ou bien sont-ils contraires à la morale juive, en raison des comportements immoraux que, ce faisant, ils pérennisent? Les juifs atteints du sida jouissent-ils de l'ensemble des droits et devoirs religieux reconnus aux autres juifs : être témoins, être comptés dans un minyan, conduire un service religieux, monter à la torah, aller au bain rituel, être enterrés selon le rituel, etc.

Si l'homosexualité fait l'objet d'une condamnation biblique non négociable, en revanche, l'attitude à l'égard des homosexuels fait l'objet d'avis nuancés: la compassion, l'amour du prochain, la possibilité donnée à chacun de se racheter, le respect de la dignité 
dû à tout être humain, fût-il pécheur ou transgresseur, le fait qu'un(e) homosexuel(le) fait partie de la communauté juive aussi longtemps qu'il/elle n'a pas été excommunié(e), constituent autant d'arguments qui doivent être pris en considération.

Mis à part le fait qu'il nous informe sur les positions juives vis-à-vis d'un phénomène contemporain apparemment sans précédent, l'intérêt de l'ouvrage tient au fait qu'il illustre de façon magistrale le mode de fonctionnement de la réflexion traditionnelle : il montre comment les dépositaires de la tradition font fonctionner et avancer cette tradition en se saisissant de faits de société supposés nouveaux ou inédits, comment ils tentent, en procédant par analogie, de les ramener à du connu aux fins de s'appuyer sur les avis des sages qui les ont précédés pour fonder et élaborer leur propre raisonnement; il montre, enfin, la capacité d'innovation que déploient ces penseurs qui, à aucun moment, ne ressentent le besoin de sortir de leur cadre théologique, éthique, normatif pour se sentir concernés par le monde qui les entoure.

Régine Azria.

\subsection{1}

FRIEDMAN (Saul S.).

Jews and the American Slave Trade. New Brunswick-Londres, Transaction Publishers, 1998, 326 p. (bibliogr., index).

Ce livre entend moins présenter une étude historique de la participation des juifs dans le commerce des esclaves noirs vers les Amériques qu'apporter une réponse à un document antisémite, The Secret Relationship between Blacks and Jews, publié en 1992 par le mouvement noir américain 'The Nation of Islam' de Louis Farrakhan. Dans le premier chapitre de l'ouvrage ici recensé, l'auteur présente le texte, le contexte dans lequel il a été rédigé, les thèses qui y sont développées (qu'il qualifie d'antihistoire) et qui l'ont incité à écrire sa propre version des faits: les auteurs de The Secret Relationship... soutiendraient, entre autres, que les juifs auraient été les principaux acteurs et responsables de la traite des Noirs déportés comme esclaves en Amérique. Ce document violemment polémique élaboré par le 'Département de Recherche Historique' de la 'Nation of Islam', instrumentaliserait ainsi, d'après l'A., dans un esprit de concurrence et de rivalité, le bénéfice à tirer du statut de 'victimes' propres aux juifs et aux Noirs. Cette confrontation illustre à sa façon la détérioration des relations entre juifs et Noirs, le sentiment d'hostilité anti-juifs qui s'est développé au sein de certains milieux noirs américains et, symétriquement, la prise de distance par rapport à la 'cause noire' observable dans certains milieux juifs. Dans sa préface, S.S.F. indique que la plupart de ses collègues historiens, spécialistes de l'histoire de l'esclavage, de l'histoire de l'Amérique ou de l'histoire juive, ont refusé de réagir et d'ouvrir une controverse publique à la parution de ce pamphlet. Ce faisant, ils auraient laissé s'intaller dans l'opinion américaine des contre-vérités qu'aucun démenti sérieux n'est venu réfuter. C'est cette réfutation qu'il entend ici nous proposer.

Si la démarche se justifie - un tel document méritait sans doute une réponse documentée mais sobre, précise et irréfutable, ne serait-ce qu'en raison de ses effets potentiellement ravageurs -, il demeure que la polémique et la passion sont bien mauvaises conseillères lorsqu'il s'agit d'établir des faits dans un souci d'objectivité. Or, l'A. a opté pour une autre forme de réponse: la recherche d'exhaustivité appuyée sur une documentation surabondante. Ce qui rend sa démonstration pesante, ennuyeuse, répétitive. C'est ainsi qu'il a cru utile de remonter jusqu'à l'Antiquité et d'accumuler les dossiers, les faits, les chiffres, les références, en reprenant la géographie, les itinéraires, les étapes de la traite des Noirs vers les Amériques, depuis les ports de départ mis en place par les grandes puissances coloniales et commerciales: la Hollande, la France (le Code Noir), l'Angleterre, jusqu'aux lieux de destination outre-Atlantique, notamment les grandes plantations de sucre et de coton. À chaque étape de sa démonstration, il tente d'évaluer la place relative des juifs dans ce commerce à partir des sources disponibles susceptibles d'apporter des informations sur leur démographie, leur activité professionnelle, la part de transactions qu'il est possible de leur imputer. Un travail de cette ampleur - point n'est besoin de reprendre ici le détail des 250 pages serrées de démonstration minutieuse entreprise à partir de dossiers historiques concrets - était-il véritablement nécessaire pour réfuter l'accusation et affirmer que les juifs n'avaient finalement joué qu'un rôle mineur dans le commerce des esclaves?

Loin de toute polémique et de toute tentative de réfutation, cette étude pose deux questions distinctes. L'une, d'ordre historique, est celle du rôle effectif des juifs dans le commerce des esclaves. C'est, on l'aura compris, la question centrale à laquelle l'A. tente, avec passion et détermination, d'apporter une réponse dans l'ouvrage ici recensé. L'autre question est une question d'actualité. Elle concerne le contexte socio-culturel dans lequel ce travail a été entrepris, un contexte marqué d'un côté par la dégra- 